\title{
Saudi Society of Maternal-Fetal Medicine guidance on pregnancy and coronavirus disease 2019
}

Yaser A. Faden, MMedEd, SBOG, Nadia A. Alghilan, MBBS, SBOG, Samiha H. Alawami, MBBS, SBOG,

Eman S. Alsulmi, MSHA, SBOG, Hythem A. Alsum, MBBS, SBOG, Yasir A. Katib, MBBS, FRCSC. Yasser S. Sabr, MHSc, SBOG,

Fadwah H. Tahir, MBBS, FRCSC. Nabeel S. Bondagji, MBBS, FRCSC.

C oronavirus disease (COVID-19) has been shown to be highly contagious and outbreaks have been reported to occur easily. Antenatal clinics and labor and delivery units are considered to be high-risk areas. The consequences of an outbreak occurring in a maternal and child health facility could be detrimental. COVID-19 is complicated to treat, unpredictable, and difficult to control. Therefore, increased health education and effective prevention and control measures must be undertaken. ${ }^{1}$

The Saudi Society of Maternal-Fetal Medicine (SSMFM) formed a task force comprising MFM experts to review available evidence concerning pregnancy and COVID-19. Practice points and expert advice were evaluated, based on the best available evidence to date. The SSMFM aimed to provide safe care for pregnant women in the Kingdom of Saudi Arabia through exploring recent evidence that may be helpful in preventing COVID-19 transmission and provide management recommendations for those who care for suspected/confirmed patients with COVID-19. Precautionary advice for healthcare workers in contact with this specific patient population has also been included in this guidance.

As of the 30th June 2020, 186,436 patients have been infected with COVID-19 in the Kingdom of Saudi Arabia, with 1599 fatalities and an average case fatality rate of $0.86 \% .{ }^{2}$ Owing to growing patient numbers, it is imperative to communicate with all obstetric healthcare providers to ensure that they are appropriately prepared for managing suspected/confirmed patients with COVID-19.

COVID-19 is due to a new strain of coronavirus, called severe acute respiratory syndrome coronavirus-2 (SARS-CoV-2). ${ }^{3}$ Since it was first identified in Wuhan, China, in late 2019, it has spread globally and has been estimated to have infected 10,429,986 patients worldwide (in 216 countries), with 508,637 fatalities and an average case fatality rate of $4.9 \%(0.2 \%-15 \%){ }^{2}$ The World Health Organization (WHO) officially declared the COVID-19 outbreak a pandemic on March 11, 2020. ${ }^{4}$

The incubation period concerning COVID-19 is approximately 2 to 14 days; however, infected persons can transmit the virus via close contact and respiratory droplets, possibly before they become symptomatic. There is limited information concerning COVID-19 and pregnancy in published scientific literature; however, one recently published article reported good maternal, fetal, and neonatal outcomes in this patient population. ${ }^{5}$

COVID-19 is primarily transmitted in humans through respiratory droplets and contact routes. Droplet transmission occurs when there is close contact with someone with respiratory symptoms (within 2 meters). Transmission occurs through the mouth, nose,

From the Department of Obstetrics and Gynecologogy (Faden), King Abdulaziz Medical City, King Saud bin Abdulaziz University for Health Sciences; from the Department of Obstetrics and Gynecology (Bondagji), King Abdulaziz University, from the Department of Obstetrics and Gynecology (Katib), Dr. Soliman Fakeeh Hospital, Jeddah; from Department of Obstetrics and Gynecology (Alghilan, Alsum), King Abdulaziz Medical City, King Saud bin Abdulaziz University for Health Sciences, from the Department of Obstetrics and Gynecology (Sabr), King Saud University, Riyadh; from the Department of Obstetrics and Gynecology (Alawami), Imam Abdulrahman Bin Faisal Hospital, Ministry of National Guard Health Affairs; from the Department of Obstetrics and Gynecology (Alsumi), King Fahd Hospital of the University, Imam Abdulrahman Bin Faisal Hospital, Dammam; and from the Department of Obstetrics and Gynecology (Katib, Tahir), Umm AlQura University, Makkah, Kingdom of Saudi Arabia.

Address correspondence and reprint request to: Dr. Yaser Faden, Chairman, Department of Obstetrics and Gynecology, KingAbdulaziz Medical City, King Saud bin Abdulaziz University for Health Sciences, Jeddah, Kingdom of Saudi Arabia.E-mail: fadenya@ngha.med.sa

ORCID ID: https://orcid.org/0000-0001-6072-7058 
or eyes. Transmission may also occur through contact with objects contaminated with the virus. Airborne transmission of COVID-19 may also be possible during aerosol-generating procedures or treatments. Fecal-oral transmission of SARS-CoV-2 has also been reported. ${ }^{6,7}$

\section{Concerns regarding COVID-19 in pregnancy}

1.1. Severity and progression during pregnancy. Pregnancy is a state of partial immunosuppression in which pregnant women are more vulnerable to viral infections, and morbidity is higher, even with seasonal influenza. Consequently, the COVID-19 pandemic may have serious effects in pregnant women. Furthermore, it is important that pregnant women and their families, as well as the general public and healthcare providers, receive the most accurate information available.

As has been observed with other related coronavirus infections (SARS-CoV and MERS-CoV) and with other viral respiratory infections, such as influenza, pregnant women might be at a greater risk for severe illness, morbidity, or mortality compared with the general population. ${ }^{8}$ A study of one series of hospitalized non-pregnant patients in China found that up to $32 \%$ of individuals developed severe pneumonia and 19\% of all infected hospitalized patients progressed to acute respiratory distress syndrome (ARDS), with mortality ranging from $1.4 \%$ to $4.3 \%$ across all cases. ${ }^{9,10}$ These figures varied according to regions and different testing strategies.

Signs and symptoms of COVID-19 during pregnancy are expected to be similar to those in the general population. The most common clinical features of COVID-19 in hospitalized patients are fever (99\%), fatigue $(70 \%)$, dry cough $(59 \%)$, anorexia $(40 \%)$, myalgia $(35 \%)$, dyspnea $(31 \%)$, and sputum production $(27 \%)$. The most serious frequent presentation of COVID-19 is pneumonia. ${ }^{11}$ A systematic review of 108 pregnancies reported that most data were collected from women presenting in the third trimester. Fever was present in $68 \%$ of patients, $34 \%$ of patients had cough, and $91 \%$ of the 108 pregnancies involved cesarean section deliveries. ${ }^{12}$

1.2. Adverse pregnancy outcomes and congenital anomalies. The lack of evidence related to vertical transmission of SARS-CoV-2 in the first trimester is a

Disclosure. Authors have no conflict of interests, and the work was not supported or funded by any drug company. limiting factor in determining the risks of teratogenicity related to the virus itself. The majority of severe cases of COVID-19 have been reported in the third trimester. ${ }^{13}$

Currently, there is a lack of evidence concerning the risk of miscarriage or early pregnancy loss in mothers infected with SARS-CoV-2. However, SARS has been reported to be associated with a high miscarriage rate of $57 \% .{ }^{14}$ This finding should be taken into consideration, as the underlying pathology between SARS-CoV-2 and SARS appears to be similar.

At present, based on limited data, there is no evidence that the virus is teratogenic and there is no increased risk of fetal congenital anomalies in pregnant women with COVID-19. Furthermore, data in relation to SARS suggest no increase in fetal congenital anomalies. ${ }^{15}$

Adverse health outcomes, including respiratory distress, prematurity, and even fetal death, have been found in infants born to mothers affected with COVID-19. However, it is unclear whether these adverse outcomes are related to COVID-19 infection itself or to the mother's condition.

1.3. Vertical transmission. Owing to the recent emergence of the COVID-19 pandemic, data are limited and vertical transmission of this virus is uncertain. Chen et $\mathrm{al}^{13}$ reported on 9 pregnant women with COVID-19 in their third trimester. In that study, samples were obtained from amniotic fluid, cord blood, and neonatal throat swabs, and 6 patients tested negative for COVID-19 for these samples. These results indicated that in women who had developed COVID-19 infection in the third trimester and had been tested, no evidence of intrauterine infection due to vertical transmission was found.

In March 2020, Schwartz reported an extensive analysis of 38 pregnant women with COVID-19, their newborn infants, and maternal-fetal transmission of SARS-CoV-2, maternal COVID-19 infections, and pregnancy outcomes. ${ }^{16}$ The analysis concluded that there were no confirmed cases of intrauterine transmission of SARS-CoV-2 from mothers with COVID-19 to their fetuses. All neonatal specimens tested using real-time polymerase chain reaction for SARS-CoV-2 were negative.

In a recent study involving 6 neonates born to mothers with COVID-19, no evidence of vertical transmission was reported. ${ }^{13}$ However, a recent report published on March 2020 by Dong et a ${ }^{17}$ described a case of a neonate born to a mother who tested positive for SARS-CoV-2 IgM, which may represent a neonatal immune response to maternal infection. In another report, Zeng et $\mathrm{al}^{18}$ reported test results concerning 3 neonates who tested positive for SARS-CoV-2 on 
nasopharyngeal and anal swabs. More recently, 2 additional cases involving newborns who tested positive for SARS-CoV-2 have been reported. ${ }^{19,20}$

Considering the limited data, newborns of mothers with COVID-19 should be monitored carefully for evidence of transmission.

\section{Pregnancy management during the COVID-19 pandemic}

2.1. Antenatal care of women not suspected or confirmed to have COVID-19. Social distancing is the most important intervention during a pandemic. ${ }^{21}$ The first priority for physicians caring for pregnant women is to prevent disease spread; therefore, the standard antenatal appointment schedule may need to be modified to minimize direct contact while maintaining adequate maternal and fetal care.

In low-risk populations, reducing the number of in-person antenatal visits is encouraged to minimize exposure and support social distancing. In the inverted pyramid of antenatal care proposed by Sonek et $\mathrm{al},{ }^{22}$ an early visit is recommended between 11 and 13 gestation weeks to determine dates, undertake prenatal blood tests, and perform risk assessment. If a patient is deemed to be low-risk, subsequent antenatal visits can be arranged at the following gestational ages: 20, 37, and 41 weeks. This model might be used as an alternative to the traditional model of care. In-person visits can involve an office visit or a home visit, depending on each healthcare institution's resources and available healthcare personnel.

Telehealth use has grown noticeably in the past few years globally and in the past few months in Saudi Arabia. Multiple successful examples have been reported from local healthcare institutions. ${ }^{23}$ One university hospital in Saudi Arabia has been communicating with patients through the WhatsApp application to address all non-urgent questions and relevant matters to minimize obstetric triage visits. Refill prescriptions are sent to patients' homes via mail delivery to avoid patients arriving at hospitals to collect their medication. Another hospital has used a simple telehealth method of telephoning the patient prior to her clinic visit. If care can be provided over the phone, the in-person visit is rescheduled to a later date. These are individual and local attempts to adapt to the global COVID-19 pandemic. There is no robust evidence to support any approach over another in implementing social distancing while providing appropriate antenatal care.

Hospitals need to understand their patient populations and resources in devising a system that provides antenatal care while enhancing social
Table 1 - Suggested antenatal visits during a COVID-19 pandemic.

\begin{tabular}{|c|c|c|}
\hline $\begin{array}{l}\text { Gestational } \\
\text { age (weeks) }\end{array}$ & Type of visit & Comments \\
\hline $11-14$ & $\begin{array}{l}\text { In-person or } \\
\text { telehealth }\end{array}$ & $\begin{array}{c}\text { Booking visit, dating ultrasound, risk } \\
\text { assessment, antenatal routine blood } \\
\text { tests } \\
\text { If telehealth, ffDNA** testing may } \\
\text { be considered instead of nuchal } \\
\text { translucency scan. }\end{array}$ \\
\hline $20-24$ & In-person & $\begin{array}{c}\text { Anatomy scan could be combined } \\
\text { with a regular prenatal visit on the } \\
\text { same day. }\end{array}$ \\
\hline $26-28$ & $\begin{array}{l}\text { In-person or } \\
\text { telehealth }\end{array}$ & $\begin{array}{l}\text { If needed, patient presents in } \\
\text { person for blood tests, OGTT } \\
\text { immunization, and anti-D. } \\
\text { Otherwise, it can be a telehealth visit. }\end{array}$ \\
\hline 32 & Telehealth** & $\begin{array}{c}\text { Should be an in-person visit with a } \\
\text { growth scan if the patient is assessed } \\
\text { as high risk."* }\end{array}$ \\
\hline $36-37$ & In-person & $\begin{array}{l}\mathrm{GBS}^{\S} \text { swab, } \mathrm{BPP}^{* \ddagger} \text { and a growth scan } \\
\text { if high risk, placental assessment for } \\
\text { previa/low-lying placenta, plan mode } \\
\text { of delivery }\end{array}$ \\
\hline 38-39 & Telehealth & $\begin{array}{l}\text { Weekly in-person visits with BPP and } \\
\text { growth scan if high risk. }{ }^{\dagger}\end{array}$ \\
\hline $40-41$ & In-person & Plan delivery if not delivered, BPP \\
\hline $\begin{array}{l}\text { 4-6 weeks } \\
\text { postpartum }\end{array}$ & Telehealth & \\
\hline
\end{tabular}

*Antenatal care is for low-risk patients. Care for high-risk patients should be individualized, including the need for earlier and more frequent biophysical profiles (BPPs). $†$ High-risk group: gestational diabetes mellitus, pre-gestational diabetes mellitus, chronic hypertension (HTN) on medications, gestational HTN, preeclampsia with no severe features in current pregnancy, systemic lupus erythematosus, hemoglobinopathies, intrauterine growth restriction (IUGR) or multiple pregnancy, previous history of severe pre-eclampsia, IUGR or prior unexplained intrauterine fetal demise. $§ G B S$ : group B streptococcus, $¥ \mathrm{BPP}$ and non-stress test, **ffDNA: fetal free DNA

distancing. A suggested care model that combines both telehealth and in-person visits is summarized in Table 1. For high-risk patients, care should be individualized and tailored to patients' needs and fetal condition.

2.2. Antenatal care for women with suspected or confirmed COVID-19. Patients' risk for COVID-19 should be assessed prior to their hospital visit for antenatal care. For suspected COVID-19-positive stable pregnant women, investigation and isolation should be implemented according to Saudi Ministry of Health $(\mathrm{MOH})$ protocols, and any antenatal care appointment should be rescheduled after 14 days. The Royal College of Obstetricians \& Gynaecologists (RCOG), London, United Kingdom recommend that all routine appointments (for example, growth scans and oral glucose tolerance tests) for women with suspected or confirmed COVID-19 should be delayed until after the recommended period of isolation. ${ }^{24}$ 
Antenatal care for high-risk pregnancies in women with suspected or confirmed COVID-19 should be individualized. In this population, when maternal or fetal monitoring cannot be delayed, appointments and fetal scans can be arranged preferably at the end of the working day. ${ }^{23}$ For hospitalized patients, a portable ultrasound machine for fetal surveillance can be assigned to these cases if hospital resources allow. Staff providing care should apply personal protective equipment (PPE) precautions, as the Saudi Center for Disease Prevention and Control guidelines have indicated. ${ }^{25}$ Clinical areas exposed to these patients should be appropriately sanitized and equipment properly disinfected.

However, concerning pregnant women with poorly controlled comorbidities who are suspected to have COVID-19, admission can be discussed by a multidisciplinary team and individualized depending on the patient's status and the institution's capacity and policies. Comorbidities include, but are not limited to, hypertension; diabetes mellitus; asthma; human immunodeficiency virus-positive; chronic heart, liver, lung, and kidney diseases; hemoglobinopathies; and patients on immunosuppressive agents.

All pregnant women confirmed as having COVID-19 should be admitted and managed as inpatients, in accordance with Saudi MOH guidelines.

2.3. Hospital care for patients with suspected or confirmed COVID-19 (Appendix 1). Patients with suspected/confirmed COVID-19 who require admission should be isolated in a negative-pressure room, preferably in hospitals with adequate facilities and multidisciplinary expertise to manage critically ill obstetric patients. Based on clinical evaluation, they should be triaged and stratified into mild, moderate, severe, and critical categories (Table 2). ${ }^{24}$

Patients should be managed by a multidisciplinary team comprising specialists in maternal-fetal medicine, infectious diseases, anesthesiology, neonatology, and intensive care (Table 3). All medical staff caring for patients with COVID-19 should use PPE, including

Table 2 - Categorization of patients with COVID-19.

\begin{tabular}{|c|c|}
\hline Mild & $\begin{array}{l}\text { Asymptomatic or mild symptoms with stable vital signs } \\
\text { and NO comorbidities }\end{array}$ \\
\hline Moderate & Mild symptoms with stable vital signs and a comorbidity \\
\hline Severe & $\begin{array}{l}\text { Symptomatic with respiratory rate } \geq 30 \text { breaths } / \mathrm{min} \\
\text { OR walking test } \mathrm{SaO}_{2} \leq 94 \% \text { OR arterial blood oxygen } \\
\text { partial pressure }\left(\mathrm{PaO}_{2}\right) / \text { oxygen concentration }\left(\mathrm{FiO}_{2}\right) \\
\leq 300 \mathrm{mmHg} \text { OR lung infiltration }>50 \% \text { of the lung field } \\
\text { within } 24-48 \text { hours }\end{array}$ \\
\hline Critical & $\begin{array}{l}\text { Shock with organ failure, respiratory failure requiring } \\
\text { mechanical ventilation or refractory hypoxemia requiring } \\
\text { extracorporeal membrane oxygenation }\end{array}$ \\
\hline
\end{tabular}

Table 3 - Management of pregnant women with confirmed COVID-19.

\begin{tabular}{|c|c|}
\hline \multicolumn{2}{|c|}{ Admission } \\
\hline Mild or moderate & Severe or critical \\
\hline $\begin{array}{l}\text { Treat symptoms - consult } \\
\text { Infectious Disease Specialist }\end{array}$ & $\begin{array}{l}\text { Treat symptoms - ICU admission, } \\
\text { decision by ICU treating team } \\
\text { - consult Infectious Disease } \\
\text { Specialist - careful consideration } \\
\text { of antibiotic or antifungal therapy, } \\
\text { according to local epidemiology }\end{array}$ \\
\hline \multicolumn{2}{|l|}{ Medications } \\
\hline $\begin{array}{l}\text { Consider starting } \\
\text { hydroxychloroquine } 400 \mathrm{mg} \\
\text { every } 12 \text { hours for } 1 \text { day, } \\
\text { followed by } 200 \mathrm{mg} \text { BID for } \\
5-7 \text { days }\end{array}$ & $\begin{array}{l}\text { Prednisolone } 40 \mathrm{mg} \text { orally } \\
\text { once daily or hydrocortisone } \\
\text { intravenously } 80 \mathrm{mg} \text { twice daily }\end{array}$ \\
\hline $\begin{array}{l}\text { If hydroxychloroquine is not } \\
\text { available: consider chloroquine } \\
600 \mathrm{mg}(10 \mathrm{mg} / \mathrm{kg}) \text { at diagnosis } \\
\text { and } 300 \mathrm{mg}(5 \mathrm{mg} / \mathrm{kg}) 12 \text { hours } \\
\text { later, followed by } 300 \mathrm{mg}(5 \mathrm{mg} / \\
\mathrm{kg}) \text { BID for } 5-7 \text { days }\end{array}$ & $\begin{array}{l}\text { Consider Remdesivir } 200 \mathrm{mg} \\
\text { loading dose (IV, within } 30 \\
\text { minutes), followed by } 100 \mathrm{mg} \\
\text { once daily for } 5-10 \text { days }\end{array}$ \\
\hline $\begin{array}{l}\text { Chloroquine phosphate } 1000 \mathrm{mg} \\
\text { at diagnosis and } 500 \mathrm{mg} 12 \\
\text { hours later, followed by } 300 \mathrm{mg} \\
\text { BID for } 5-7 \text { days }\end{array}$ & $\begin{array}{l}\text { Consider Interferon beta-1b } \\
8 \text { MIU subcutaneously on } \\
\text { alternative days for } 3 \text { doses (may } \\
\text { also be considered for mild- } \\
\text { moderate disease) }\end{array}$ \\
\hline \multicolumn{2}{|c|}{ Precautions } \\
\hline Avoid ibuprofen & Avoid ibuprofen \\
\hline $\begin{array}{l}\text { Laboratory tests and work-up: } \\
\text { CBC, urea/electrolytes, creatine, } \\
\text { CRP, LFTs, chest x-ray with } \\
\text { additional G6PD screening }\end{array}$ & $\begin{array}{l}\text { Laboratory tests and work-up: CBC, } \\
\text { urea/electrolytes, creatinine, CRP, } \\
\text { LFTs, chest x-ray, with additional } \\
\text { G6PD screening }\end{array}$ \\
\hline $\begin{array}{l}\text { If chloroquine will be used, } \\
\text { perform ECG every } 3 \text { days if } \\
\text { initial QTc is } 400-500 \mathrm{~ms} \text {, } \\
\text { and biochemistry according to } \\
\text { underlying disease }\end{array}$ & $\begin{array}{l}\text { If }>7 \text { days have passed since the } \\
\text { patient's symptoms first appeared, do } \\
\text { not administer interferon beta- } 1 \mathrm{~b}\end{array}$ \\
\hline \multicolumn{2}{|c|}{$\begin{array}{l}\text { BID: twice a day, CBC: complete blood count, CRP: C-reactive } \\
\text { protein, ECG: electrocardiogram, G6PD: glucose-6-phosphate- } \\
\text { dehydrogenase, ICU: intensive care unit, LFT: liver function tests, } \\
\text { NST: non-stress test }\end{array}$} \\
\hline
\end{tabular}

head covers, gowns, N95 masks, goggles, gloves, and shoe covers.

\section{COVID-19 therapy in pregnancy}

Currently, there is no medication that has been proven to be safe and effective for treating COVID-19.

3.1. Chloroquine/hydroxychloroquine and azithromycin. Chloroquine and hydroxychloroquine are effective in inhibiting SARS-CoV-2 infection in vitro. Hydroxychloroquine is observed to have a more potent antiviral activity. ${ }^{26}$ The use of chloroquine has been included in treatment guidelines from China's National Health Commission and has been claimed to be associated with reduced progression of disease and duration of symptoms. ${ }^{27,28}$ However, there are no published primary data to support these claimed associations. 
There are limited clinical data on either of these medications. In an open-label study of 36 patients with confirmed COVID-19, hydroxychloroquine administration (200 mg twice daily for 10 days) was associated with a $70 \%$ negative result of a nasopharyngeal PCR swab at day 6 compared with a $12.5 \%$ negative result in patients with no specific treatment. ${ }^{29}$ In this study, azithromycin was used in combination with hydroxychloroquine.

Despite the limited clinical data and given the relative safety of short-term use of hydroxychloroquine, the lack of known effective interventions and antiviral activity, some evidence (based on expert opinion) has shown that it is reasonable to use this agent in hospitalized patients with severe or risk for severe infection, particularly if they are not eligible for other clinical trials. ${ }^{30}$ Optimal dosing is uncertain; various regimens are being used, including $400 \mathrm{mg}$ twice daily on day one then once daily for 5 days, $400 \mathrm{mg}$ twice daily on day one then $200 \mathrm{mg}$ twice daily for 4 days, and $600 \mathrm{mg}$ twice daily on day one then $400 \mathrm{mg}$ daily for 4 days. ${ }^{31}$ Considering the safety of hydroxychloroquine/ chloroquine use in pregnancy, it is reasonable to apply the same regimen as that of non-pregnant patients (Table 3). Regarding concerns about the risk of death due to arrythmia from single or combined use of these medications, the absolute magnitude is smaller than the potential benefit from treatment of COVID-19. The use of high-dose chloroquine $(600 \mathrm{mg}$ twice daily for 10 days) and the combination of hydroxychloroquine and azithromycin is not recommended because of the potential for toxicities. ${ }^{32,33}$

3.2. Antiviral treatment. Antiviral treatment has been routinely used to treat patients with COVID-19 infection in China and is also recommended for pregnant patients. Combination therapy with antiproteases, namely, lopinavir/ritonavir, is currently not recommended, as it has unfavorable pharmacodynamics, and there is lack of evidence on its effectiveness from clinical trials. ${ }^{31}$ A recent systematic review of 2 randomized trials and 21 observational studies concluded that it is uncertain whether lopinavir/ ritonavir and other antiretroviral medication improve clinical outcomes in patients with severe symptomatic disease. $^{34}$ A more recent randomized controlled trial, RECOVERY, showed no beneficial effect of lopinavir/ ritonavir in patients hospitalized with COVID-19. ${ }^{35}$

Remdesivir is a novel nucleotide analog active against SARS-CoV-2 in vitro and related coronaviruses (including SARS and MERS-CoV) both in vitro and in animal studies. ${ }^{36}$ Several randomized trials are ongoing to evaluate the efficacy of remdesivir for moderate or severe COVID-19. Preliminary data have led expert panels to recommend remdesivir for the treatment of COVID-19 in patients with severe disease, but not in those with mild or moderate disease. ${ }^{37}$ It is unknown whether remdesivir is safe for use during pregnancy and lactation.

3.3. Statins. Statins are one of the proposed medications to treat patients with COVID-19. Generally, they are contraindicated in pregnancy. A risk-benefit analysis should be conducted before using investigational therapeutic agents in pregnant women outside of clinical trials. ${ }^{38}$

3.3. Convalescent plasma therapy. There is insufficient evidence in support of convalescent plasma, SARS-CoV-2-specific immune globulin, and non-SARS-CoV-2-specific intravenous immunoglobulin (IVIG), and these are currently not recommended for use except in the context of a clinical trial. ${ }^{39}$

3.4. Antibacterial treatment. Empiric antimicrobial treatment for bacterial pneumonia may be considered for patients with suspected or confirmed COVID-19. SARS-CoV-2 may also cause extensive lung damage, which increases the risk of secondary bacterial pneumonia. Prompt initiation of antibiotics is indicated if there is evidence of secondary bacterial infection or if bacterial sepsis is suspected.

3.5. Glucocorticoids. Glucocorticoids have been associated with an increased mortality risk in patients with influenza and delayed viral clearance in patients with MERS-CoV infection. There is no clear evidence of benefit in the management of SARS, while there is convincing evidence of adverse short- and long-term harm. ${ }^{40}$

The RECOVERY trial has recently showed reduced 28-day mortalityin hospitalized patientswith COVID-19 on respiratory support. ${ }^{41}$ The Saudi Ministry of Health recently updated their protocol for managing patients with suspected/confirmed COVID-19. Pregnant and breastfeeding patients with severe or critical disease are recommended to receive prednisolone $40 \mathrm{mg}$ orally once daily or intravenous hydrocortisone $80 \mathrm{mg}$ twice daily instead of dexamethasone. ${ }^{42}$

3.6. Supportive therapy. Adequate rest, hydration, nutritional support, antipyretics, and water and electrolyte balance are essential supportive measures for patients with COVID-19. Vital signs and oxygen saturation are needed to be closely monitored. Depending on disease severity and extent of hypoxemia, supplemental oxygen inhalation (60\%-100\% concentration at a rate of $40 \mathrm{~L} / \mathrm{min}$ ) should be given 
through a high-flow nasal cannula. Intubation and mechanical ventilation, or even extra-corporeal membrane oxygenation (ECMO), may be required to maintain oxygenation. Complications may include septic shock, acute kidney injury, and virus-induced cardiac injury. Consequently, it is important to check arterial blood gases, lactate levels, renal function, liver function, and cardiac enzymes, as indicated according to the clinical situation.

The use of non-steroidal anti-inflammatory drugs (NSAIDs) early in the course of the disease has been observed to have a negative effect on disease outcome. ${ }^{43}$ These findings are based on case reports of 4 young patients who received NSAIDs early in the course of infection and who experienced severe disease. Conversely, there are no clinical or population-based data to confirm the risks of using NSAIDs. The European Medicines Agency and the WHO do not recommend that NSAIDs be avoided when clinically indicated. ${ }^{44,45}$ The Saudi Centers for Disease Control and Prevention has recommended the avoidance of ibuprofen. ${ }^{23}$ In light of these concerns, the SSMFM encourages the use of acetaminophen in place of NSAIDs for reduction of fever.

\section{Obstetric medication concerning patients with COVID-19}

4.1. Tocolytics. Given the uncertainty regarding the effect of NSAIDs on COVID-19, indomethacin should be avoided currently. Therefore, nifedipine may be used as an alternative in patients presenting with preterm labor and requiring tocolysis. Other tocolytic agents may be contemplated with caution, and interaction with other medications should be considered.

4.2. Betamethasone/Dexamethasone. Steroids for fetal lung maturity should be used cautiously in pregnant women with severe COVID-19 disease who are at $<34$ weeks of gestation. Worsening morbidity of viral pneumonia has been associated with the administration of steroids. ${ }^{46}$ However, steroids for fetal lung maturity may be considered for patients with mild to moderate disease who are at $<34$ gestation weeks.

4.3. Progesterone. Given the lack of evidence on the effects of progesterone on COVID-19 and adverse pregnancy outcomes associated with early progesterone cessation, progesterone use may be continued in cases of mild disease. ${ }^{47}$ The use of progesterone in severe cases should be individualized.

4.4. Magnesium sulfate (MgSO4). Magnesium sulfate is usually indicated in the obstetric setting for maternal eclampsia prophylaxis or fetal neuroprotection. There is a lack of evidence concerning the effects of
MgSO4 on pregnant patients with COVID-19. This medication, excreted by the kidneys, may affect the respiratory status of the patient. Magnesium sulfate may be given to patients with mild disease. In patients with severe disease, administration needs to be individualized depending on the medical condition. Possible drug interactions also need to be considered.

4.5. Thromboprophylaxis. There is increasing evidence that patients with COVID-19 infection are at high risk of developing venous thromboembolism (VTE). In a study conducted in China, COVID-19 patients who received unfractionated heparin (UFH)/ low-molecular-weight heparin (LMWH) had significantly better survival than those who did not. Pregnancy is also a well-known risk factor for VTE. Less mobilization of pregnant women due to the COVID-19 pandemic and hospitalization are likely to further increase the risk.

The recommended doses of UFH/LMWH were based on body weight and D-dimer measurements. ${ }^{48}$ D-dimer levels in pregnancy differ from those in a non-pregnant state. This should be considered when calculating the risk score assessment for VTE and prescribing LMWH for pregnant women. The SSMFM recommends that a thrombosis expert be included in the care of patients with suspected/ confirmed COVID-19. The SSMFM also recommends commencement of LMWH thromboprophylaxis for all pregnant women with confirmed COVID-19 who are admitted to hospital and who are not expected to deliver within 12 hours. It is recommended to continue postpartum LMWH thromboprophylaxis for at least 10 days postpartum; however, this may be extended to 6 weeks, depending on the patient's clinical status upon discharge and on the presence of other comorbidities.

4.6. Low-dose aspirin. Low-dose aspirin is widely used in obstetrics for pregnant women (example, prevention of pre-eclampsia, fetal growth restriction, and recurrent fetal loss). There is lack of evidence regarding risks associated with aspirin use in pregnant women with suspected/confirmed COVID-19. The SSMFM advises continuation of low-dose aspirin for pregnant women without COVID-19 infection.

Low-dose aspirin use in pregnant women with suspected/confirmed COVID-19 infection should be individualized based on the clinical indication, gestational age, and maternal condition. ${ }^{49}$ The SSMFM advises to withhold low-dose aspirin in patients with severe-critical COVID-19 infection.

\section{Managing chronic medications}

Patients receiving immunomodulatory agents. 
Immunocompromised patients with COVID-19 are at an increased risk for severe disease and the decision to discontinue prednisone, biologics, or other immunosuppressive drugs in the setting of SARS-CoV-2 infection must be determined on a case-by-case basis. For individuals with underlying conditions who require treatment with these agents and are without COVID-19, there is no evidence that routinely discontinuing treatment is of any benefit. Furthermore, discontinuing these medications may result in a loss of response when the agent is reintroduced. This approach is supported in guidance from various dermatology, rheumatology, and gastroenterology societies. ${ }^{50-52}$

\section{Critically ill patients}

Critically ill patients with severe organ damage, in particular, respiratory and renal failure, will require a multidisciplinary approach in an inpatient setting and in a critical care unit. These patients are managed case-by-case, depending on their condition, as they may require hemodialysis with correction of electrolyte imbalance, respiratory ventilatory support, and wide spectrum antibiotic coverage. Priority is given to stabilizing the maternal condition. Extracorporeal life support during pregnancy is considered effective and safe for the mother and the fetus. Survival rate for the mother is $77.8 \%$ and $65.1 \%$ for the fetus. ${ }^{53}$

Obstetric care is undertaken by a general obstetrician, or a maternal-fetal medicine specialist, based on availability. This care involves fetal monitoring if the pregnancy can be continued, and pregnancy termination if fetal or maternal conditions indicate otherwise.

\section{Obstetrical factors determining timing of delivery:}

A. Gestational age. A previable gestational age ( $<23-24$ weeks) pregnancy may need to be terminated to improve the maternal condition if agreed upon by a panel of experts (obstetrician and intensivist/ pulmonologist) who consider continuation of pregnancy life-threatening.

For early preterm fetuses (23-24 weeks to $33+6$ weeks), although pregnancy can be terminated for maternal indications, counseling should include discussing the risks and benefits of administering steroids as well as $\mathrm{MgSO} 4$ for neuroprotection if the maternal condition allows.

Planning of delivery for a reasonably mature fetus ( $\geq 34$ weeks) should be individualized according to the patient's condition.

B. Maternal condition. The maternal medical condition should be evaluated by internal medicine and intensive care specialists, and should include an assessment of the medical and social risks of contracting SARS-CoV-2 and the presence of comorbidities. For diagnosis and evaluation of the disease progress, the use of computed tomography scanning and plain chest radiographs are permitted, if indicated, regardless of the fetal gestational age, with the use of abdominal shield protection. Based on a comprehensive evaluation, a decision should be made to determine whether expeditious delivery is needed to improve the maternal condition. If the maternal medical condition necessitates an urgent delivery, a cesarean section can be performed with epidural, spinal, or general anesthesia. Pediatricians should be involved if preterm delivery is decided.

C. Fetal assessment parameters. If the maternal medical condition allows trial of vaginal delivery, then continuous fetal monitoring is advised during labor. A cesarean section is only recommended for the standard obstetrical indications.

D. Risk of vertical transmission. If a decision is taken to expedite delivery, then delivery needs to be performed regardless of the risk of vertical transmission for patients in this category.

\section{Labor considerations for suspected/ confirmed patients with COVID-19 (Appendix 2)}

There is no strong evidence that termination of pregnancy or early delivery will improve the overall maternal outcome or decrease the mortality rate. However, previous experience with $\mathrm{H} 1 \mathrm{~N} 1$ and SARS-CoV showed some improvement in terms of ventilation and oxygenation for those with severe respiratory failure on mechanical ventilation. ${ }^{54} \mathrm{~A}$ multidisciplinary team review with the family should be conducted to make the decision, considering the risk of prematurity and perinatal morbidity and mortality when a patient is $<37$ weeks' pregnant.

The mode of delivery should not be affected owing to COVID-19. Cesarean birth should be performed in line with standard obstetric indications unless the patient's respiratory condition requires urgent delivery. Instrumental delivery may be considered to expedite delivery and shorten the second stage of delivery.

Patients in active labor should be admitted to an isolation room, followed with an assessment of the severity status of COVID-19, and then a multidisciplinary approach to patient care implemented.

The distance between a healthcare professional (HCP) involved in a delivery and the patient is less than the standard distance advised; therefore, full PPE 
is recommended. Care should be taken to minimize the number of unnecessary healthcare personnel present in the labor room. The presence of a support person intrapartum is not encouraged. If they are permitted to be present, they should wear full PPE and sign a risk-ofexposure consent form.

Given the risk of asymptomatic carrier transmission, it is recommended that all patients and their providers in every delivery unit wear surgical masks during each encounter. ${ }^{49}$ This recommendation may be difficult to implement because of supply shortage. Full droplet precautions should be applied, including wearing gloves, a gown, and a surgical mask with a face shield when attending to a patient with respiratory symptoms. An N95 mask should be worn alongside PPE droplet precautions for any patient with suspected or confirmed COVID-19; and for any patient, irrespective of respiratory symptoms, during indispensable aerosolizing procedures. ${ }^{52}$ These precautions are also recommended for the second stage of labor. ${ }^{55}$

Continuous external electronic fetal monitoring should be undertaken and, if possible, the use of fetal scalp electrodes should be avoided. A cesarean section should not be delayed if fetal well-being is questionable, as fetal blood sampling is discouraged. COVID-19 is not an indication for cesarean delivery.

The use of surgical N95 respirators is reserved for HCPs exposed to airborne and fluid hazards (examples, splashes and sprays). A face shield over a standard N95 respirator should be used in case of surgical N95 respirator shortage.

There is no contraindication to provide regional analgesia including epidural or spinal anesthesia. However, general anesthesia should be avoided as much as possible as intubation is associated with aerosol generation.

Intubation is known as an aerosol-generating procedure, for which the surgical team should wear full PPE and wear N95 respirators for cesarean delivery, ${ }^{56}$ even in cases of spinal-epidural anesthesia, as noted in Saudi Anesthesia Society Guidelines, ${ }^{57}$ as there is always the possibility of converting from regional to general anesthesia. Delayed cord clamping and early cleaning of the neonate should still be encouraged. ${ }^{55}$

Other good practice points include postponing elective cesarean deliveries until the patient is cleared as negative and is, therefore, no longer contagious. Moreover, it is advisable to consider scheduling cesarean delivery for suspected/confirmed patients with COVID-19 at the end of the operating room (OR) list. Appropriate precautions should be made during the transfer of the patient from the labor and delivery room to the $\mathrm{OR}$ and from the $\mathrm{OR}$ to the post-anesthesia care unit to minimize exposure.

Simulation-based training (example, obstetric drills) is strongly recommended in labor and delivery units as part of their preparedness plan. Such activities have been associated with improvement in staff skills, patient safety, and quality of care. Improvement of clinical performance is attributed to identification of system errors during training, followed by timely correction. ${ }^{58}$

During the pandemic period, the SSMFM discourages home births for all patients to ensure application of protective measures and availability of required resources and equipment in the event of urgent interventions.

\section{COVID-19 postpartum care}

8.1. Postpartum maternal care. The location for postpartum care will be determined according to the

Table 4 - Postpartum supportive care for women with confirmed COVID-19.

\begin{tabular}{|c|c|c|}
\hline \multirow[b]{2}{*}{ Type of care } & \multicolumn{2}{|c|}{ Maternal statu } \\
\hline & Mild or moderate & Severe or critical \\
\hline $\begin{array}{l}\text { Psychological } \\
\text { support }\end{array}$ & $\begin{array}{l}\text { Recommended. } \\
\text { Active surveillance } \\
\text { for postpartum } \\
\text { depression and } \\
\text { mental health is } \\
\text { recommended. }\end{array}$ & $\begin{array}{l}\text { Recommended. } \\
\text { May need further } \\
\text { assessment for post- } \\
\text { traumatic stress } \\
\text { syndrome and } \\
\text { management. }\end{array}$ \\
\hline $\begin{array}{l}\text { Venous } \\
\text { thromboprophylaxis } \\
\text { risk assessment }\end{array}$ & $\begin{array}{l}\text { COVID-19 is an } \\
\text { additional risk }\end{array}$ & $\begin{array}{l}\text { Individualize care. } \\
\text { (exclude DIC and } \\
\text { bleeding risk) }\end{array}$ \\
\hline Breast care & $\begin{array}{l}\text { Breast pump is } \\
\text { recommended (if } \\
\text { breastfeeding is } \\
\text { desired). }\end{array}$ & $\begin{array}{l}\text { Milk suppression is } \\
\text { recommended. }\end{array}$ \\
\hline Pain control & Avoid NSAIDs. & Avoid NSAIDs. \\
\hline $\begin{array}{l}\text { Contraceptive } \\
\text { counseling }\end{array}$ & $\begin{array}{l}\text { Offer while an in- } \\
\text { patient (to avoid } \\
\text { postnatal visit) or } \\
\text { during a telehealth } \\
\text { visit after recovery } \\
\text { when the infectivity } \\
\text { and isolation period } \\
\text { have passed }\end{array}$ & $\begin{array}{l}\text { Defer until the patient } \\
\text { is well }\end{array}$ \\
\hline Visitors & $\begin{array}{l}\text { Discourage visitors. } \\
\text { Follow local policy. } \\
\text { Full PPE required. }\end{array}$ & $\begin{array}{l}\text { Discourage visitors. } \\
\text { Follow local policy. } \\
\text { Full PPE required. }\end{array}$ \\
\hline Discharge & $\begin{array}{l}\text { Maintain as an } \\
\text { in-patient until } \\
\text { two negative } \\
\text { nasopharyngeal swab } \\
\text { results are obtained }\end{array}$ & $\begin{array}{l}\text { Prolonged care is } \\
\text { required until the } \\
\text { critical status has } \\
\text { improved and } 2 \text { negative } \\
\text { nasopharyngeal swab } \\
\text { results are obtained }\end{array}$ \\
\hline
\end{tabular}

EBM: evidence-based medicine, NICU: neonatal intensive care

unit, PPE: personal protective equipment, NSAID: non-steroidal anti-inflammatory drugs, DIC: disseminated intravascular coagulation 
condition and stability of the patient. Suspected/ confirmed stable patients with mild symptoms can be nursed in the postpartum ward with appropriate isolation until the infection is cleared (Table 4). Patients who require respiratory support are likely to be treated and managed in an intensive care unit (ICU). A venous thromboprophylaxis risk assessment should be followed as per the patient's medical condition and local institution policies.

Pain control should follow standard guidelines. It has recently been hypothesized that NSAIDs such as ibuprofen could aggravate COVID-19 symptoms; ${ }^{59}$ however, the United States FDA does not discourage the use of ibuprofen based on currently available information. ${ }^{60}$

Severe illness during pregnancy can increase the risk of mental health illnesses. Women who have experienced severe maternal morbidity have significantly greater odds of being treated for a psychiatric disorder. ${ }^{61}$ Maternal-neonatal separation in COVID-19 cases may cause anxiety to parents and lead to maternal depression. ${ }^{62}$ Emotional, psychological support, and counseling should be provided. Vigilant monitoring for postpartum depression is recommended. Women who have been critically ill may need post-traumatic stress syndrome support.

Standard contraceptive counseling should be provided as appropriate while the patient remains in hospital. No COVID-19-specific data are available concerning the choice of contraception regimen.

8.2. Neonatal care. Maternal health status is relevant in deciding the extent of mother/neonate contact. The issue of segregation should be discussed thoroughly with the patient and family, and individualized care is recommended (Table 5).

Neonates delivered by mothers with confirmed COVID-19 should be categorized as suspected cases and isolated, in line with Saudi $\mathrm{MOH}$ guidelines. ${ }^{63}$ There is a lack of consensus regarding mother/neonate contact. The RCOG has advised that neonates not otherwise requiring special care be kept together with their mothers in the immediate postpartum period. ${ }^{24}$ $\mathrm{Qia}^{64}$ and Liang et $\mathrm{al}^{65}$ recommended temporary separation of the mother and her neonate to prevent close contact, to avoid virus transmission. This separation period is recommended to continue for a minimum of 2 weeks. ${ }^{64,65}$ The American College of Obstetricians and Gynecologists Clinical Advisory Board adopted a United States Centers for Disease Control and Prevention recommendation that facilities should consider temporary separation of confirmed or
Table 5 - Neonatal care for babies born from mothers with COVID-19.

\begin{tabular}{|c|c|c|}
\hline Type of care & Negative & Positive \\
\hline Isolation & $\begin{array}{l}\text { Negative pressure } \\
\text { room }\end{array}$ & $\begin{array}{c}\text { Negative pressure room/ } \\
\text { NICU }\end{array}$ \\
\hline Feeding & EBM/formula & EBM/formula \\
\hline $\begin{array}{l}\text { Neonate discharge } \\
\text { (to a healthy } \\
\text { caregiver) }\end{array}$ & $\begin{array}{l}\text { When fit for } \\
\text { discharge, } \\
\text { continue isolation at } \\
\text { home for } 14 \text { days. }\end{array}$ & $\begin{array}{l}\text { Repeat samples } \\
\text { every 48-72 hours. } \\
\text { Discharge when well } \\
\text { and when two negative } \\
\text { nasopharyngeal swab } \\
\text { results are obtained, and } \\
\text { continue isolation at } \\
\text { home for } 14 \text { days. }\end{array}$ \\
\hline $\begin{array}{l}\text { Parents and } \\
\text { caregiver education }\end{array}$ & $\begin{array}{l}\text { Written and } \\
\text { verbal education } \\
\text { concerning standard } \\
\text { precautions and } \\
\text { hand hygiene, } \\
\text { including clear } \\
\text { instructions } \\
\text { regarding when to } \\
\text { seek medical care. }\end{array}$ & $\begin{array}{l}\text { Written and verbal } \\
\text { education concerning } \\
\text { standard precautions } \\
\text { and hand hygiene, } \\
\text { including clear } \\
\text { instructions regarding } \\
\text { when to seek medical } \\
\text { care. }\end{array}$ \\
\hline
\end{tabular}

EBM: evidence-based medicine, NICU: neonatal intensive care unit

suspected patients with COVID-19 until the mother has been confirmed as being no longer infectious. ${ }^{66,67}$

The SSMFM prefers to err on the side of caution in considering segregation, as the spread method and transmission from the mother to the neonate have not yet been well established. Temporary separation is likely to facilitate care for both a mother and a neonate, and minimize healthcare workers' contact and exposure risks, especially given the current universal shortage of PPE.

Chen et $\mathrm{al}^{8}$ found no evidence that this virus was excreted in breast milk in a limited number of tested samples. However, direct breastfeeding is not recommended, as it requires long and close contact. ${ }^{66}$ There is conflicting limited evidence in the literature regarding breastfeeding. The SSMFM recommends a detailed discussion with the mother concerning risks and benefits of breastfeeding in patients with COVID-19, covering the limited available data concerning excretion of the virus in the breastmilk, the potential presence of antibodies, the risks of infection from the neonatal care provider, and the care needed while handling the neonate to avoid infection as well as alternative feeding options, such as expressed breast milk and formula. Ultimately, the family will have to make an informed choice between expressed breast milk and formula, regardless of which strict infection control criteria are applied.

Natural or medical methods for milk suppression may be considered if a patient chooses not to express 
breast milk or if medically indicated. Neonates born to mothers with suspected or confirmed COVID-19 are considered to be high risk and should have clear discharge criteria. The family should be educated appropriately and provided with information, as mentioned in Table 5.68,69

\section{References}

1. Zhu H, Wang L, Fang C, Peng S, Zhang L, Chang G, et al. Clinical analysis of 10 neonates born to mothers with 2019-nCoV pneumonia. Transl Pediatr 2020; 9: 51-60.

2. World Health Organization. Coronavirus disease 2019 (COVID-2019) pandemic. [Updated 2020. Assessed 6 June 2020]. Available from URL: https://www.who.int/emergencies/ diseases/novel-coronavirus-2019

3. World Health Organization (WHO). Naming the coronavirus disease (COVID-19) and the virus that causes it. [Updated 2020. Assessed 2020 June 6]. Available from URL: https:// www.who.int/emergencies/diseases/novel-coronavirus-2019/ technical-guidance/naming-the-coronavirus-disease-(covid2019)-and-the-virus-that-causes-it

4. World Health Organization. Rolling updates on coronavirus disease (COVID-19). [Updated 2020 June 29. Assessed 2020 June 6]. Available from URL: https://www.who.int/ emergencies/diseases/novel-coronavirus-2019/events-as-theyhappen

5. Yu N, Wei L, Kang Q, Xiong Z, Wang S, Lin X, et al. Clinical features and obstetric and neonatal outcomes of pregnant patients with COVID-19 in Wuhan, China: a retrospective, single-centre, descriptive study. Lancet Infect Dis 2020; 20: 559-564.

6. Hindson J. COVID-19: faecal-oral transmission? Nat Rev Gastroenterol Hepatol 2020; 17: 259-259.

7. Xu Y, LiX, Zhu B, Liang H, Fang C, Gong Y, et al. Characteristics of pediatric SARS-CoV-2 infection and potential evidence for persistent fecal viral shedding. Nat Med 2020; 26: 502-505.

8. Schwartz DA, Graham AL. Potential maternal and infant outcomes from coronavirus 2019-nCoV (SARS-CoV-2) infecting pregnant women: lessons from SARS, MERS, and other human coronavirus infections. Viruses 2020; 12: 194.

9. Society for Maternal-Fetal Medicine (SMFM); Sarah DottersKatz, MD, MMHPE; and Brenna L. Hughes, MD, MSc On March 11, 2020, Coronavirus (COVID-19) and pregnancy: what maternal-fetal medicine subspecialists need to know. [Updated 2020. Assessed 2020 March 11]. Available from URL: https://s3.amazonaws.com/cdn.smfm.org/media/2262/ COVID19_PDF.pdf/

10. Power J. Coronavirus: South Korea's aggressive testing gives clues to true fatality rate. South China Morning Post. [Updated 2020. Assessed 2020 March 20]. Available from URL: https://www. scmp.com/week-asia/health-environment/article/3065187/ coronavirus-south-koreas-aggressive-testing-gives/

11. Wang D, Hu B, Hu C, Zhu F, Liu X, Zhang J, et al. Clinical characteristics of 138 hospitalized patients with 2019 novel coronavirus-infected pneumonia in Wuhan, China. JAMA 2020; 323: 1061-1069.

12. Zaigham M, Andersson O. Maternal and perinatal outcomes with COVID-19: a systematic review of 108 pregnancies. Acta Obstet Gynecol Scand 2020; 99: 823-829.
13. Chen H, Guo J, Wang C, Luo F, Yu X, Zhang W, et al. Clinical characteristics and intrauterine vertical transmission potential of COVID-19 infection in nine pregnant women: a retrospective review of medical records. Lancet 2020; 395: 809-815.

14. Wong SF, Chow KM, Leung TN, Ng WF, Ng TK, Shek CC, et al. Pregnancy and perinatal outcomes of women with severe acute respiratory syndrome. Am J Obstet Gynecol 2004; 191 : 292-297.

15. Shek CC, Ng PC, Fung GP, Cheng FW, Chan PK, Peiris MJ, et al. Infants born to mothers with severe acute respiratory syndrome. Pediatrics 2003; 112: e254.

16. Schwartz DA. An analysis of 38 pregnant women with COVID-19, their newborn infants, and maternal-2 fetal transmission of SARS-CoV-2: maternal coronavirus infections and pregnancy outcomes. Arch Pathol Lab Med 2020; 144: 799-805.

17. Dong L, Tian J, He S, Zhu C, Wang J, Liu C, et al. Possible vertical transmission of SARS-CoV-2 from an infected mother to her newborn. JAMA 2020; 323: 1846-1848.

18. Zeng L, Xia S, Yuan W, Yan K, Xiao F, Shao J, et al. Neonatal early-onset infection with SARS-CoV-2 in 33 neonates born to mothers with COVID-19 in Wuhan, China. JAMA Pediatr 2020; 174: 722-725.

19. Woodward A. A pregnant mother infected with the coronavirus gave birth, and her baby tested positive 30 hours later. Business Insider. [Updated 2020 February 5. Accessed 2020 March 30]. Available from URL: https://www.businessinsider.com/wuhancoronavirus-in-infant-born-from-infected-mother-2020-2

20. Murphy S. Newborn baby tests positive for coronavirus in London. The Guardian. [Updated 2020 March 14. Accessed 2020 March 30]. Available online: https://www.theguardian. com/world/2020/mar/14/newborn-baby-tests-positive-forcoronavirus-in-london

21. Anderson RM, Heesterbeek H, Klinkenberg D, Hollingsworth TD. How will country-based mitigation measures influence the course of the COVID-19 epidemic? Lancet 2020; 395: 931-934.

22. Sonek J, Kagan K, Nicolaides K. Inverted pyramid of care. Clin Lab Med 2016; 36: 305-317.

23. Alaboudi A, Atkins A, Sharp B, Balkhair A, Alzahrani M, Sunbul T. Barriers and challenges in adopting Saudi telemedicine network: the perceptions of decision makers of healthcare facilities in Saudi Arabia. I Infect Public Health 2016; 9: 725-733.

24. RCOG, Coronavirus (COVID-19) infection in pregnancy information for healthcare professionals Version 5. Accessed on March 28, 2020. Available from URL: https://www.rcog.org. uk/coronavirus-pregnancy/

25. Weqaya. Saudi Center for Disease Prevention and Control. Coronavirus Disease 19 (COVID-19) Guidelines. [Updated 2020 May. Accessed on 2020 March 20]. Available from URL: https:/www.moh.gov.sa/Ministry/MediaCenter/Publications/ Documents/Coronavirus-Disease-2019-Guidelines-v1.2.pdf/

26. Yao X, Ye F, Zhang M, Cui C, Huang B, Niu P, et al. In vitro antiviral activity and projection of optimized dosing design of hydroxychloroquine for the treatment of severe acute respiratory syndrome coronavirus 2 (SARS-CoV-2). Clin Infect Dis 2020; ciaa237.

27. Gao J, Tian Z, Yang X. Breakthrough: chloroquine phosphate has shown apparent efficacy in treatment of COVID-19 associated pneumonia in clinical studies. Biosci Trends 2020; 14: 72-73. 
28. Colson P, Rolain JM, Lagier JC, Brouqui P, Raoult D. Chloroquine and hydroxychloroquine as available weapons to fight COVID-19. Int J Antimicrob Agents 2020; 55: 105932.

29. Cortegiani A, Ingoglia G, Ippolito M, Giarratano A, Einav S. A systematic review on the efficacy and safety of chloroquine for the treatment of COVID-19. J Crit Care 2020; 57: 279-283.

30. Gautret P, Lagier J-C, Parola P, Hoang VT, Meddeb L, Mailhe $\mathrm{M}$, et al. Hydroxychloroquine and azithromycin as a treatment of COVID-19: results of an open-label non-randomized clinical trial. Int J Antimicrob Agents 2020: 105949.

31. Centers for Disease Control or Prevention. Therapeutic options for patients with COVID-19. [Updated 2020 June 16. 2020 Accessed March 22]. Available from: https://www.cdc.gov/ coronavirus/2019-ncov/hcp/therapeutic-options.html

32. National Institutes of Health. COVID-19 treatment guidelines. Chloroquine or Hydroxychloroquin. [Updated 2020 June 16. Accessed 2020 June 3]. Available from URL: https:// www.covid19treatmentguidelines.nih.gov/antiviral-therapy/ chloroquine-or-hydroxychloroquine/

33. National Institutes of Health. COVID-19 treatment guidelines. Hydroxychloroquine plus Azithromycin. [Updated 2020 May 12. Accessed 2020 June 3]. Available from URL: https:// www.covid 19 treatmentguidelines.nih.gov/antiviral-therapy/ hydroxychloroquine-plus-azithromycin/

34. Ford N, Vitoria M, Rangaraj A, Norris SL, Calmy A, Doherty M. Systematic review of the efficacy and safety of antiretroviral drugs against SARS, MERS, or COVID-19: initial assessment. J Int AIDS Soc 2020; 23: e25489.

35. RECOVERY. No clinical benefit from use of lopinavir-ritonavir in hospitalized COVID-19 patients studied in RECOVERY. Recovery Trial. [Updated 2020. Accessed 2020 June 29]. Available from URL: https://www.recoverytrial.net/news/noclinical-benefit-from-use-of-lopinavir-ritonavir-in-hospitalisedcovid-19-patients-studied-in-recovery

36. Sheahan TP, Sims AC, Graham RL, Menachery VD, Gralinski LE, Case JB, et al. Broad-spectrum antiviral GS-5734 inhibits both epidemic and zoonotic coronaviruses. Sci Transl Med 2017; 9: eaal3653.

37. National Institutes of Health. What's New in the Guidelines. [Updated 2020 June 25. Accessed 2020 June 3]. Available from URL: https://www.covid19treatmentguidelines.nih.gov/ whats-new/

38. Fedson DS, Opal SM, Rordam OM. Hiding in plain sight: an approach to treating patient with severe COVID-19 infection. mBio 2020; 11: e00398-20.

39. National Institutes of Health. Convalescent Plasma and Immune Globulins. [Updated 2020 May 12. Accessed 2020 June 3]. Available from URL: https://www.covid19treatmentguidelines. nih.gov/immune-based-therapy/convalescent-plasma-andimmune-globulins/

40. Russell CD, Millar JE, Baillie JK. Clinical evidence does not support corticosteroid treatment for 2019-nCoV lung injury. Lancet 2020; 395: 473.

41. Horby P, Lim WS, Emberson J, Mafham M, Bell J, Linsell L, et al. Effect of Dexamethasone in Hospitalized Patients with COVID-19: Preliminary Report. medRxiv 2020; 2020: 1-24.

42. Ministry of Health. Saudi MoH Protocol for Patients Suspected of/Confirmed with COVID-19. Supportive care and antiviral treatment of suspected or confirmed COVID-19 infection. [Updated 2020 June 17. Accessed 2020 June 19]. Available from URL: https:/www.moh.gov.sa/Ministry/MediaCenter/ Publications/Documents/MOH-therapeutic-protocol-forCOVID-19.pdf
43. Day M. Covid-19: ibuprofen should not be used for managing symptoms, say doctors and scientists. BMJ 2020; 368: m1086.

44. European Medicines Agency. EMA gives advice on the use of non-steroidal anti-inflammatories for COVID-19. [Updated 2020 March 18.Accessed 2020 June 29]. Available from URL: https://www.ema.europa.eu/en/news/ema-gives-advice-usenon-steroidal-anti-inflammatories-covid-19

45. Science Alert. Updated: WHO now doesn't recommend avoiding ibuprofen for COVID-19 symptoms. [Updated 2020 March 17. Accessed 2020 March 19]. Available from URL: https://www.sciencealert.com/who-recommends-to-avoidtaking-ibuprofen-for-covid-19-symptoms

46. Zhou F, Yu T, Du R, Fan G, Liu Y, Liu Z, et al. Clinical course and risk factors for mortality of adult inpatients with COVID-19 in Wuhan, China: a retrospective study. Lancet 2020; 395: 1054-1062.

47. Rebarber A, Ferrara LA, Hanley ML, Istwan NB, Rhea DJ, Stanziano GJ, et al. Increased recurrence of preterm delivery with early cessation of 17-alpha-hydroxyprogesterone caproate. Am J Obstet Gynecol 2007; 196: 224.e1-224.e4.

48. National Institutes of Health. Thromboprophylaxis and anticoagulation in COVID-19 infection. [Updated 2020 May. Accessed 2020 June 29]. Available from URL: https://www.wsh. nhs.uk/covid-staff-zone/Guidelines-SOPs-clinical-info/Docs/ Clinical-guideline/CG10393-COVID-Thromboprophylaxisand-Anticoagulation-in-COVID-19-infections.pdf

49. American College of Obstetricians and Gynecologists. COVID-19 FAQs for Obstetrician-Gynecologists, Obstetrics. [Updated 2020. Accessed 2020 March 25]. Available form URL: https://www.acog.org/clinical-information/physicianfaqs/covid-19-faqs-for-ob-gyns-obstetrics

50. The American Academy of Dermatology. Article Title. [Updated 2020. Accessed 2020 March 18]. Available from URL: https://assets.ctfassets.net/1 ny4yoiyrqia/PicgNuD0I pYd9MSOwab47/023ce3cf6eb82cb304b4ad4a8ef50d56/ Biologics_and_COVID-19.pdf

51. American College of Rheumatology. [Updated 2020 June 14. Accessed 2020 March 18]. Available from URL: https://www. rheumatology.org/announcements

52. Joint GI Society message: COVID-19 clinical insights for our community of gastroenterologists and gastroenterology care providers. [Updated 2020 March 16. Accessed on March 18, 2020]. Available from URL: https://www.gastro.org/pressrelease/joint-gi-society-message-covid-19-clinical-insights-forour-community-of-gastroenterologists-and-gastroenterologycare-providers

53. Moore SA, Dietl CA, Coleman DM. Extracorporeal life support during pregnancy. I Thorac Cardiovasc Surg 2016; 151: 1154-1160.

54. Chen ZL, Zhang WJ, Lu Y, Guo C, Guo ZM, Liao CH, et al. From SARS-CoV to $2019-\mathrm{nCoV}$ outbreak: similarities in the early epidemics and prediction of future trends. Chin Med J (Engl) 2020; 133: 1112-1114.

55. Palatnik A, McIntosh JJ. Protecting labor and delivery personnel from COVID-19 during the second stage of labor. Am J Perinatol 2020; 37: 854-856.

56. SOGC COVID-19 Infectious Disease Committee Statement (March 13, 2020) Coronavirus (COVID-19) Infection in Pregnancy, Information for healthcare professionals, version 5. [Updated 2020 May 14. Accessed 2020 June 29]. Available from URL: https://sogc.org/en/-COVID-19/en/content/ COVID-19/COVID-19.aspx 
57. Alyamani O, Abushoshah I, Tawfeeq N, Al Dammas F, Algurashi F. Considerations and recommendations for obstetric anesthesia care during COVID-19 pandemic - Saudi anesthesia society guidelines. Saudi J Anaesth 2020; 14; 359-364.

58. Amatullah AF. Using interprofessional simulation-based training to improve management of obstetric emergencies: a systematic review. Clin Simul Nurs 2018; 14: 45-53.

59. Fang L, Karakiulakis G, Roth M. Are patients with hypertension and diabetes mellitus at increased risk for COVID-19 infection? Lancet Respir Med 2020; 8: e21.

60. Centers for Disease Control and Prevention. Interim considerations for infection prevention and control of coronavirus disease 2019 (COVID-19) in inpatient obstetric healthcare settings. [Updated 20 May 2020. Viewed 29 March 2020]. Available from URL: https:/www.cdc.gov/ coronavirus/2019-ncov/hcp/inpatient-obstetric-healthcareguidance.html

61. Wall-Wieler E, Carmichael SL, Urquia ML, Liu C, Hjern A. Severe maternal morbidity and postpartum mental healthrelated outcomes in Sweden: a population-based matchedcohort study. Arch Womens Ment Health 2019; 22: 519-526.

62. Wang L, Shi Y, Xiao T, FU J, Feng X, Mu D, et al. Chinese expert consensus on the perinatal and neonatal management for the prevention and control of the 2019 novel coronavirus infection. Ann Transl Med 2020; 8: 47.

63. Saudi MOH COVID-19 in Pregnancy Rapid Response Guidelines Version 1.1. [Updated 2020. Accessed 2020 March 31]. Available form URL: https://www.moh.gov.sa/Ministry/ MediaCenter/Publications/Documents/COVID-19-INPREGNANCY-MOH-Protocol.pdf/
64. Qia J. What are the risks of COVID-19 infection in pregnant women? Lancet 2020; 395: 760-762.

65. Liang H, Acharya G. Novel corona virus disease (COVID-19) in pregnancy: what clinical recommendations to follow? Acta Obstet Gynecol Scand 2020; 99: 439-442.

66. The American College of Obstetricians and Gynecologist. Clinical Guidance-Practice Advisory-Novel Coronavirus 2019 (COVID-19). [Updated 2020 July 1. Accessed 2020 March 28]. Available from URL: https://www.acog.org/clinical/ clinical-guidance/practice-advisory/articles/2020/03/novelcoronavirus-2019

67. Centers for Disease Control and Prevention. Discontinuation of home isolation for persons with COVID-19 (Interim Guidance). [Udpated 2020 May 29. Accessed on March 17, 2020]. Available from URL: https://www.cdc.gov/ coronavirus/2019-ncov/hcp/disposition-in-home-patients.html

68. Saudi $\mathrm{MOH}$ Guideline for Neonate Born to Mothers with Suspected or Confirmed COVID-19 Infection. [Updated 2020 April 12. Accessed 2020 June 4]. Available from URL: https://www.moh.gov.sa/Ministry/MediaCenter/Publications/ Documents/Guideline-for-Neonate-born-to-COVID-19Mother.pdf

69. FAQs: Management of Infants Born to Mothers with Suspected or Confirmed COVID-19. [Updated 2020. Accessed on 2020 June 4]. https://services.aap.org/en/pages/2019-novelcoronavirus-covid-19-infections/clinical-guidance/faqsmanagement-of-infants-born-to-covid-19-mothers/ 